\title{
TARI SEUDATI INONG SEBAGAI WUJUD REPRESENTASI KESETARAAN GENDER DIKABUPATEN ACEH BESAR
}

\author{
Nadra Akbar Manalu ${ }^{1 *}$, Fifie Febryanti Sukman* \\ Jurusan Seni Pertunjukan \\ Institut Seni Budaya Indonesia (ISBI) Aceh \\ Jl. Transmigrasi, Gampong Bukit Meusara, Kec. Kota Jantho,Kab. Aceh Besar, Kode Pos 23911 \\ Aceh. Indonesia \\ Email:nadraakbarmanalu@isbiaceh.ac.id,fifiefebryantisukman@isbiaceh.ac.id
}

\begin{abstract}
Abstrak
Aceh erat kaitannya dengan syariat Islam. Kesenian dimanfaatkan sebagai media dakwah untuk mens yiarkan agama Islamkepada seluruh mas yarakat diberbagai wilay ah Provinsi Aceh. Tari Seudati Inong merupakan tarian tradisonal masyarakat Aceh yang ditarikan oleh perempuan dan gerakannya merupakan imitasi dari Tari Seudati y ang ditarikan oleh laki- laki. Tari Seudati Inong biasa juga disebut sebagai Tari Laweut, tarian ini berkembang di pesisisr utara hingga timur daerah Aceh dengan menggambarkan semangat, perjuangan dan doa-doa dalam syair tari tersebut. Tujuan dalampenelitian ini membahas bagaimana bentuk tari Seudati Inong di Kabupaten Aceh Besar dan mengetahui bagaimana tari Seudati Inong sebagai wujud reperesentasi kes etaraan gender di Kabupaten Aceh Besar. Pengumpulan data dan penelitian dilakukan dengan beberapa tahap seperti tinjauan pustaka untuk mendapatkan berbagai informasi tertulis, observasi, wawancara dan dokumentasi untuk mengamati secara langsung perkembangan dan pristiwa yang terjadi dilapangan dan lokasi penelitian berada di Desa Cucum, Kecamatan Kota Jantho, Kabupaten Aceh Besar. Data-data yang telah didapatkan kemudian dianalis a sehingga menghasilkan hasil penelitian lalu disajikan ke dalam bentuk deskriptif. Tari Seudati Inong merupakan salah satu wujud darirepresentasi kesetaraan gender yang telah ada sejak zaman dahulu. Mengingat Aceh yang merupakan daerah dengan syariat Is lam, tarian ini muncul dan berkembang ditengah mas yarakat dengan wujud representasi kesetaraan gender, gerakkan tarian dari tari Seudati yang dilakukan oleh laki-laki dan saat ini dengan perkembangan zaman ditarikan oleh perempuan. Tari Seudati Inong tidak memiliki perbedaan gerak dengan tari Seudati, perbedaan hanya berada padagerak pukulan tangan dimana laki-laki pukulannya di bagian dada dan perempuan di bagian paha. Pola lantai juga memiliki kesamaan dan jugasemangat daritariannya sama dengan tari Seudati.
\end{abstract}

Kata Kunci: seudati inong, kesetaraan gender, Aceh.

\begin{abstract}
Aceh culture is closely related to Islamic law. Art is used as a medium of preaching to broadcast Islam to all communities in various regions of Aceh Province. Seudati Inong dance is a traditional Acehnese dance that is danced by women and its movement is an imitation of Seudati Dance which is danced by men. Seudati Inong dance, also known as Laweut Dance, is a dance that develops in the northerm to eastern coast of Aceh by depicting the spirit, struggle and prayers in the lyrics of the dance. The purpose of this research is to discuss how the Seudati Inong dance form in Aceh Besar District and to find out how the Seudati Inong dance is a form of representation of gender equality in Aceh Besar District. Data collection and research were carried out in several stages such as literature review to obtain various written information, observations, interviews and documentation to directly observe developments and events that occurred in the field and the research location was in Cucum Village, Jantho City District, Aceh Besar District. The data that has been obtained are then analyzed so that the results of the research are then presented in a descriptive form. Seudati Inong dance is a form of representation of gender equality that has existed since ancient times. Given that Aceh is an area with Islamic law, this dance appears and develops in the community with a form of representation of gender equality, moving the dance from the Seudati dance which is performed by men and nowadays it is danced bywomen. Seudati Inong dance has no different movements with Seudati dance, the onlydifference is in the motion of the hand strokes where the male punches on the chest and the female on the thigh. The floor pattern also has similarities and the spirit of the dance is the same as that of the Seudati dance.
\end{abstract}

Keywords: seudati inong, gender equality, Aceh. 


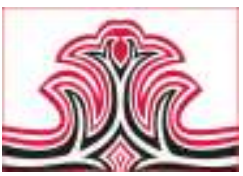

PENDAHULUAN

Aceh merupakan salah satu Provinsi yang terletak di Pulau Sumatera dengan keunikan dan keis timewaannya sendiri. Aceh dalam sejarahnya menjadi wilayah pertama di Nusantara menerima ajaran agama Islam. Sehingga kebudayaan Aceh erat kaitannya dengan syariat Is lam. Penghayatan terhadap ajaran Is lam dan fatwa ulama melahirkan budaya-budaya Aceh yang tercermin dalam adat istiadatnya. Kemudian dipraktikkan dan dikembangakan serta dilestarikan secara turun-temurun dari satu generasi kepada generasi selanjutnya. Wilayah daerah Aceh sangat kental akan kepercayaan terhadap Agama Islam sehingga muncul filosofi yang berkembang pada masyarakat Aceh yaitu "adat ngoen hukum lagee zat ngon sifat" yang artinya adat deng an hukumseperti zat dan sifat. Berkaitan denga filosofi masyarakat Aceh pada umumnya dan khususnya para ulama menjadikan kesenian sebagai media dakwah untuk mensyiarkan agama Islam kepada seluruh masyarakat di berbagai wilayah Provinsi Aceh.

Kesenian dalam kosmo peradaban manusia adalah suatu bentuk penyanggakebudayaan agar kebudayaan ters ebut tetap eksis ditengah mas yarakat pemiliknya. Pernyataan tentang seni sebagai suatu aktifitas budaya yang tidak bis a dipisahkan dari unsur- unsur Agama Is lam pada masyarakat Aceh dapat dilihat hampir semua jenis kesenian Aceh selalu mengandung nilainilai ag ama di dalamnya. Salah satu contohnya adalah Tari Seudati Inong yang merupakan kesenian asal Desa Cucum, Kecamatan Kota Jantho, Kabupaten Aceh Besar.

Tari Seudati Inong merupakan tarian yang ditarikan oleh perempuan dan gerakannya merupakan imitasi dari Tari Seudati yang ditarikan oleh laki-laki. Tari Seudati Inong merupakan tarian yang sifatnya heroik sesuai dengan kisah dan latar belakang Tari Seudati yang ditarikan oleh laki-laki. Sebagai satu-satunya tarian yang bentuk geraknya berbeda dengan tarian lain yang ditarikan oleh perempuan di Aceh, Tari Seudati Inong merupakan salah satu wujud dari representasi kesetaraan gender yang telah ada sejak zaman dahulu. Mengingat Aceh yang merupakan daerah dengan Syariat Is lam, tarian ini muncul dan berkembang ditengah masyarakat dengan wujud representasi kesetaraan gender.

Kesetaraan gender di Aceh telah ada sejak zaman penjajahan mengingat Aceh merupakan salah satu daerah yang berjuang melawan penjajahan pada zaman dahulu dan memiliki pejuang wanita seperti
Gorga : Jurnal Seni Rupa

Volume 09 Nomor 02 Juli-Desember 2020

p-ISSN: 2301-5942 | e-ISSN: 2580-2380

Cut Nyak Dien atau Malahayati bersama para janda atau yang biasa disebut Inong Bale. Melihat bahwa pada zaman dahulu perempuan di Aceh tidak lagi membentuk stereotipe bahwa perempuan dilabeli sebagai "ibu rumah tangga" yang berdampak merugikan mereka dari segala bidang. Akan tetapi, dengan melihat para pejuang-pejuang wanita di Aceh yang telah mematahkan stereotipe tersebut dan membuktikan bahwa perempuan juga bisa berandil dalamperjuangan melawan penjajah. Kes adaran akan kesetaraan gender di masa lalu kemudian digunakan oleh pegiat seni di Aceh ke dalam bentuk sebuah tarian yang dikembangkan dari Tari Seudati ke Tari Seudati Inong yang ditarikan oleh perempuan. Tari Seudati Inong ini sangat menerik dilihat dari Bentuk Penyajiannya yang saat ini terus dilestarikan oleh Sanggar Seni Atjeh Meutjehu yang berada di Jalan Bineh Blang No. 52 Desa Cucum Kecamatan Kota Jantho Kabupaten Aceh Besar dengan melestarikan tarian Seudati Inong sebagai wujud representasi kesetaraan gender yang dikemas dalam bentuk pertunjukan tari.

Berdasarkan dari uraian diatas dapat kita rumuskan beberaparumusan mas alah dalam penelitian inis seperti, Bagaimana Bentuk Penyajian Tari Seudati Inong di Kabupaten Aceh Besar dan Bagaimana Tari Seudati Inong Sebagai Wujud Representasi Kesetaraan Gender di Kabupaten Aceh Besar. Adapun tujuan dilakukanya penelitian Tari Seudati Inong sebagai wujud representasi kesetaraan gender di kabupaten Aceh Besar ini adalah mengetahui dan mendeskripsikan bagaimana bentuk penyajian tari Seudati Inong di Kabupaten Aceh Besar, mendeskripsikan bagaimana tari Seudati Inong sebagai wujud representasi kesetaraan gender di Kabupaten Aceh Besar. Manfaat dilakukanya penelitian ini diantaranya adalah untuk menambah wawas an mas yarakat mengenai tari Seudati Inong di Kabupaten Aceh Besar, sebagai upaya untuk menjaga pelestarian tari Seudati Inong khususnya di Kabupaten Aceh Besar, sebagai bahan refrensi untuk penelitian selanjutnya.

\section{KAJIAN TEORI}

\section{Bentuk Penyajian}

Melihat tariSeudati Inong sebagai wujud representasi gender, hal ini menarik peneliti untuk melihat terlebih dahulu bagaiman bentuk penyajian tari Seudati Inong. Peneliti menggunakan teori bentuk dari Maryono (2012:25) Bentuk merupakan peraduan daribeberapa unsur atau komponen yang bersifat fisik, saling mengait dan terintegrasi dalam suatu kesatuan. sebagai bentuk seni yang dipertunjukan atau ditoton 
masyarakat, tari dapat dipahami sebagai bentuk yang memiliki unsur-unsur atau komponen-komponen das ar yang s ecara vis ual dapat ditangkap dengan indra manusia. Menurut Jazuli 2008:11 Pembentukan tari memiliki unsur-unsur pokok yaitu gerak, ruang dan waktu. Uns ur-unsur tersebut akan terlihat jelas apabila dilihat dalam sebuah tarian kelompok. Tarian memiliki unsur-unsur pendukung atau pelengkap sajian tari antara lain adalah musik iringan, tata busana, tata rias, tema, tempat pentas atau sinar dan tata surya. Penyajian menurut Murgiyanto 2018:51 merupakan proses yang menunjukan dari satu kesatuan atas beberapa komponen atau unsur yang saling berkaitan. Bentuk penyajian adalah wujud fis $\mathrm{ik}$ yang ditampilkan dalam suatu pertunjukan tari, yang telah tersusun secara berurutan untuk memberikan sebuah pertunjukan yang memuaskan kepada penonton.

Dari pembahasan diatas tari Seudati Inong merupkan susunan gerak yang menarik, memiliki bentuk yang diadopsi dari gerakan tari Seudati. Ketegasan pada gerak tari Seudati yang ditarikan oleh laki-laki juga dapat dilihat dalam pertunjukan tari Seudati Inong sebagai wujud semangat dari perempuan Aceh. Unsur-unsurpendukung menjadi keunikan dalamtari ini. Pakian, makeup dan iringan vocal, serta betuk gerakan yang ketegasan juga memiliki kesamaan antara tari Seudati dengan Seudati Inong.

\section{Teori Representasi}

Dalam penelitian ini representasi merupakan gambaran dari pemikiran Struart hall yaitu, pertama penggunaan bahasa untuk mengatakan sesuatu yang penuh makna tentang atau untuk mempresentasikan dunia dengan penuh makna kepada orang lain. Kedua bagian penting dalam sebuah proses yang dengan makna diproduksi dan dipertukarkan diantara para anggota sebuah kebudayaan. Ketiga, produksi makna dari konsep yang ada dalam pikiran kita melalui bahasa (dalam udoyo 2011:58). Tari Seudati Inong sebagai wujud representasi dengan perubahan pengunaan penyebutan tari Seudati menjadi Seudati Inong, yang dikenal sebagai bentuk tarian tradis ional Aceh dari penari laki-laki beralih ditarikan oleh perempuan, namun tidak mengubah es ensi dari tarian ters ebut sebagai tari yang menggambarkan semangat masyarakat Aceh.

\section{METODE PENELITIAN \\ 1.Pendek atan Penelitian}

Pada pelakasnaan penelitian ini, peneliti menggunakan metode kualitatif. Metode penelitian kualitatif adalah metode penelitian yang bersifat
Gorga : Jurnal Seni Rupa

Volume 09 Nomor 02 Juli-Desember 2020

p-ISSN: 2301-5942 | e-ISSN: 2580-2380

des kriptif dan cendrung menggunakan analisa dalam proses penelitian, diamana peneliti adalah sebagai instrumen kunci. Teknik pengumpulan data bers ifat induktif/kualitatif, dan hasil penelitian kualitatif lebih menekankan makna dari pada generalisasi.

\section{Lokasi}

Lokasi penelitian ini dilakukan di Desa Cucum Kecamatan Kota Jantho yang terletak di Kabupaten Aceh Besar. Peneliti juga akan mencari informasi dari sanggar seni Atjeh Meutjehu yang mengetahui kesenian tari tersebut serta salah satu seniman yang pernah mengikuti penataan atau menarikan tari Seudati Inong untuk perbandingan data.

\section{Metode Pengumpulan Data}

Metode pengumpulan data merupakan langkah yang paling strategis/suatu tujuan dalampenelitian, karena tujuan utama dari penelitian adalah mendapatkan data, tanpa mengetahui teknik pengumpulan data, maka peneliti tidak akan mendapatkan data yang memenuhi standar data yang ditetapkan. (Sugiono, 2014:24).

\section{1). Observasi}

Observasi dalampelaksanaan, peneliti turun langsung ke lapangan dan melakukan pengamatan terhadap suatu aktifitas yang sedang berlangsung dan berjalan sesuai kajian objek dengan menggunakan alat indranya, dan juga dilakukan dengan mengumpulkan data dengan cara sesuai prosedur, s ehingga penelitian dapat menemukan hasil yang maks imal secara valid. Selain itu, peneliti juga telah melakukan observasi pengamatan lansung dengan bejalan meliputiaktivitas perhatian suatu objek pada Tari Seudati Inong dikalangan masyarakat Desa Cucum, Kecamatan Kota Jantho, Kabupaten Aceh Besar dengan melakukan pengumpulkan data agar memperoleh gambaran-gambaran yang lebih akurat.

\section{2). Wawancara}

Dalam wawancara ini selain harus membawa instrumen sebagai pedoman untuk wawancara, maka pengumpulan data juga dapat menggunakan alat bantu seperti, buku, pulpen,dan alat rekam dari handphone supaya dapat membantu dalam pelaks anaan wawancara menjadi lancar. Wawancara y ang telah ditujukan kepada beberapa informan yang akan memberikan informasi mengenai Tari Seudati Inong yang mereka ketahui dan dapat membantu menjawab semua rumus an mas alah dalam penelitian ini. 


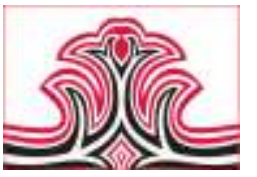

3). Dokumentasi

Dokumen merupakan catatan peristiwa yang sudah berlalu. Dokumentasi digunakan untuk mengg ali data baik dari hasil wawancara maupun observasi Dokumentasi dilakukan oleh peneliti dalam bentuk berupa catatan atau tulisan-tulisan berkaitan dengan penelitian, surat-surat pendukung, dan mengambil beberapa foto, menggunakan kamera untuk mendokumentasikan objek peneliti agar dapat menjadi data tambahan yang berhubungan dengan penelitian.

\section{Teknik Analisis Data}

Data yang di dapatkan di lapangan kemudian dianalis is. Adapun tahapan dalam analisi data adalah sebagai berikut:

\section{1). Reduksi}

Pada tahapan reduksi, data yang telah di dapatkan melalui pengamatan langsung di lapangan kemudian dipilah dan difokuskan kepada data yang penting. Proses reduksi berlangsung terus menerus selama proses penelitan.

\section{2). Penyajian Data}

Data dan informasi yang di dapatkan dilapangan dikumpulkan, maka data dan informasi tersebut disusun didistorsi berdasarkan kelompoknya dan dilakukan analisis sehingga memungkinkan adanya kesimpulan sementara yang terjadi pada saat proses reduksi.

\section{3). Verifikasi dan Kesimpulan}

Verifikasi dan kesimpilan merupakan tahapan terakhir dari teknik analasis data. Pada tahap ini datadata yang telah dianalisis kemudian akan ditarik sebuah kesimpulan.

\section{Diagram Alir Penelitian}

Adapun diagrampenelitian berdasarkan metode yang digunakan dalam penelitian tari Seudati Inong sebagai wujud representasi kesetaraan gender yaitu sebagai berikut:
Gorga : Jurnal Seni Rupa

Volume 09 Nomor 02 Juli-Desember 2020

p-ISSN: 2301-5942 | e-ISSN: 2580-2380

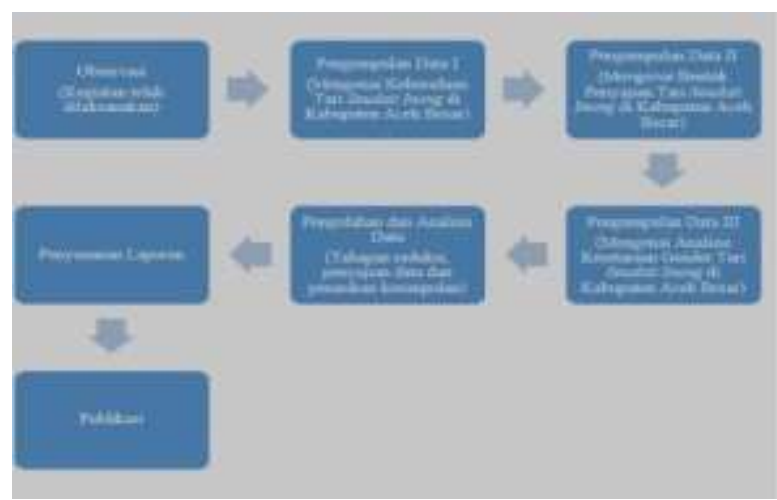

Gambar 1. Diagram Alur Penelitian

(Sumber: Nadra Akbar Manalu, 2020)

\section{HASIL DAN PEMBAHAS AN}

\section{Hasil}

\section{1). Kabupaten Aceh Besar}

Provinsi Aceh terdiri dari 23 Kabupaten/Kota yang terdiri dari 17 Kabupaten salah satunya Kabupaten Aceh Besar (Rusdi 2019:7). Pembagian wilayah di Kabupaten Aceh Besar yaitu bagian utara dibatasi oleh Selat Malaka tetapi jug ga berbatasan dengan Kota Banda Aceh. Secara administratif wilayah kabupaten Aceh Bes ardibagi menjadi 23 Kecamatan yang terdiri dari 68 mukim, 600 gapong/desa, dan 4 kelurahan. Desa Cucum merupakan salah satu desa dari 12 desa y ang berada diwilay ah administratif Kecamatan Kota Jantho. Mas yarakat di desa Cucum mayoritas mata pencahariannya yaitu bertani dan beternak. Kondisi perkampungan/desa yang berpola memusat menjadi ciri dari perkampungan di Kabupaten Aceh Besar termasuk desaCucum. Lokasiy ang tenang, sejuk dan penduduk yang tidak begitu ramai menjadi tempat tinggal yang nyaman bagi mas yarakat desa Cucum Selain suasana yang nyaman, kebudayaan dan kesenian beriringan terus terjada di desa tersebut. Bapak Buniamin (nasrasumber) merupakan salah satu penduduk atau mas yarakat di desa Cucumyang terus melestarikan kesenian-kesenian di desa Cucum.

Bukti upaya beliau untuk terus meles tarikan kesenian yaitu dengan mendirikan sebuah sanggar seni yang bernama Atjeh Meutjehu. Sanggar tersebut diperuntukkan bagi anak-anak dan para remaja di desa Cucum untuk belajar kesenian khususnya tari. Berbagai tarian tradisional di ajarkan oleh Bapak Buniamin, salah satunya tari Seudati Inong. Menurut Buniamin (wawancara tanggal 21 Agustus 2020) tari Seudati Inong pertama kali ada di des a Cucumkarena beliaulah yang membawanya dan mengenalkan tarian tersebut kepada mas yarakat. Ketertarikan mas yarakat terhadap tarian Seudati Inong menjadikan tarian ini terus dikenal hingga menjadi suatu identitas kesenian dari Kabupaten Aceh Besar. 


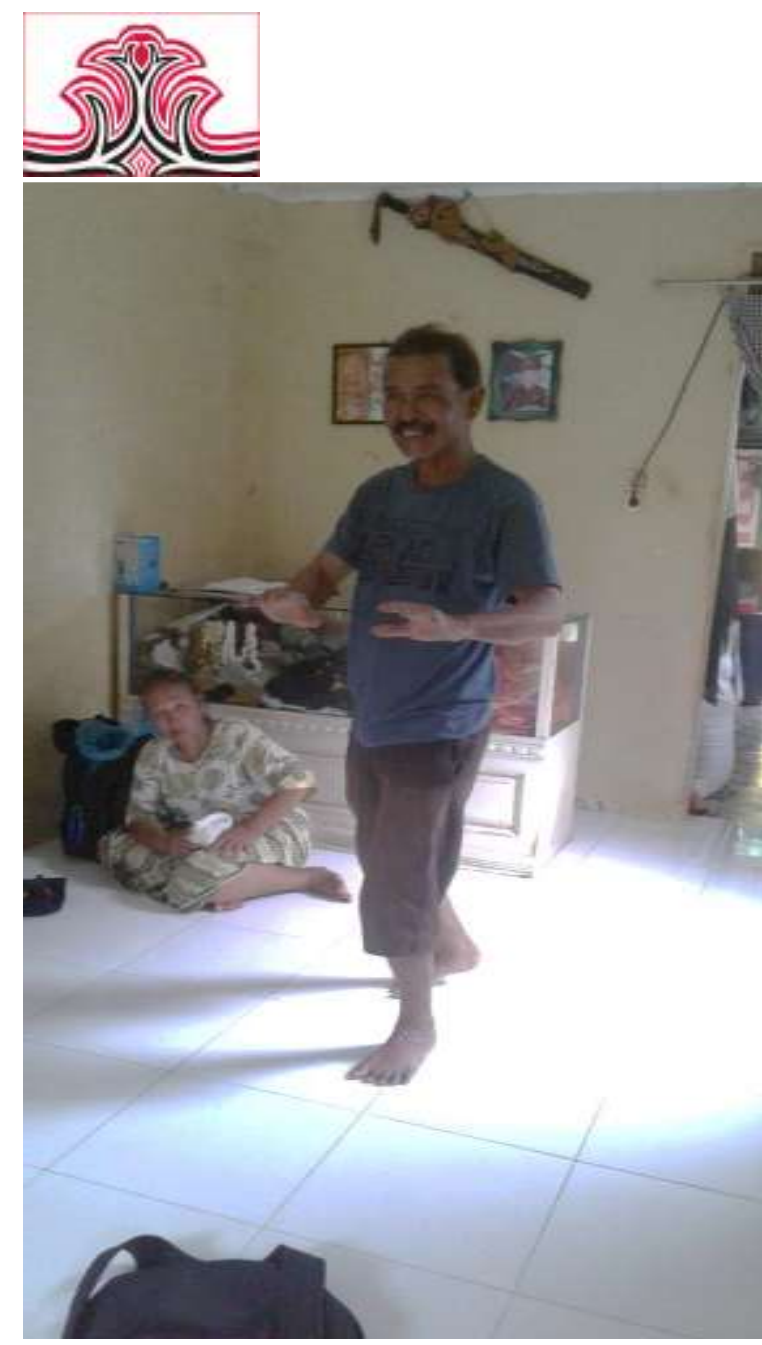

Gambar 2. Bapak Buniamin Seniman dan Pendiri Sanggar Seni Atje Meutjehu.

(Sumber. Fatimah Zuhra, 2020)

\section{2). Kesenian di Kabupaten Aceh Besar}

Kesenian merupkan sebuah etnisitas budaya masyarakat Aceh Besar, kesenian s ampai s aatini terus "hidup" dan berkembang di daerah ini. Adapun macam-macam kesenian tersebut di antaranya adalah; serune kale, Rapai Pulot, nasib (pantun), sendratari cakra donyo iskandar muda, tari-tari tradisional diantaranya tari peuron engkot, ratoh talo, seudati inong, tari likok pulo. Tari Seudati Inong berkembang di Kabupaten Aceh Besar tepatnya di desa Cucum Sanggar seni Atjeh Meutjehu terus melestarikan kesenian tersebut. Minat masyarakat dengan tarian tersebut sangat tinggi karena bentuk penyajian yang menarik dimana penarinya adalah perempuan dengan gerakan yang energi yang menggambarkan semangat kaum perempuan Aceh. Tari Seudati Inong terus berkembang berdampingan dengan tari-tari tradisional lainnya termasuk tari seudati. Kehidupan yang religius dengan mematuhi atura-aturan Is lam menjadikan tarian di Aceh sebagai media dakwah. Melalui syair dari tari Seudati Inong terdapat pesan yang disampaikan. Kedudukan penari perempuan sama dengan laki-laki dalam menarikan tarian Seudati Inong yang merupakan imitasi dari tari Seudati yang ditarikan oleh kaum laki-laki. Ini menandakan
Gorga : Jurnal Seni Rupa

Volume 09 Nomor 02 Juli-Desember 2020 p-ISSN: 2301-5942 | e-ISSN: 2580-2380

kesenian khusunya tari di Aceh peran perempuan sama kuatnya dengan kaumlaik-laki dalam haluntuk memperjuangkan kehidupan yang tercermin dari tari Seudati Inong walaupun kodratnya laki-laki adalah pemimpin, namun wanita mampu untuk terus berjuang menjalani kehidupan, mempertahankan kehormatan dan ikut andil untuk menyampaikan pesan-pesan kebaikan melalui media kesenian tari.

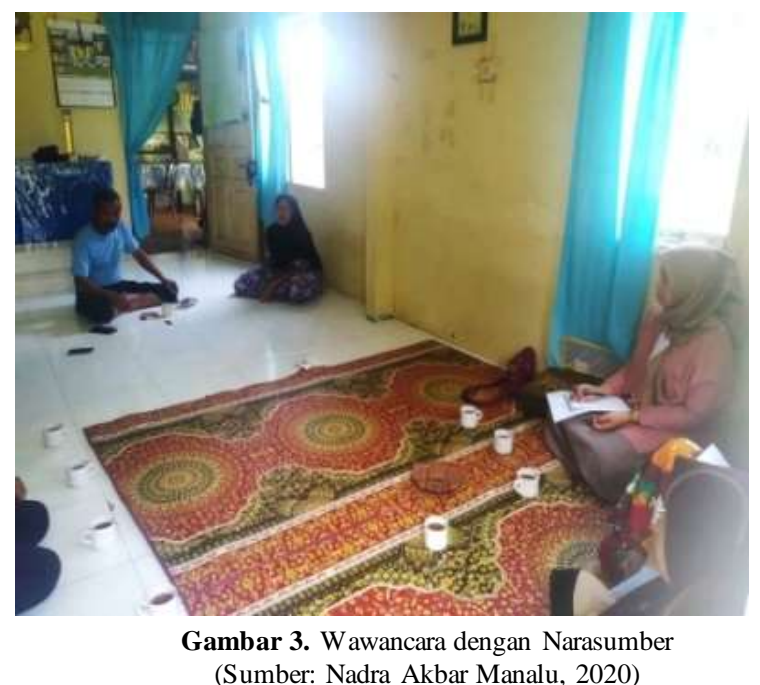

\section{3). Aspek-Aspek Tari Seudati Inong} (1). Penari

Berdasarkan jumlah penari, Tari Seudati Inong memiliki jumlah penari sebanyak 8 orang. Sesuai dengan penamaannya Inong dalam Bahasa Aceh artinya perempuan sehinggajenis kelamin daripenari Seudati Inong adalah perempuan. Tari Seudati Inong merupakan jenis tari berkelompok dengan penari sebany ak 8 orang dan 1 orang syeh yang berada di luar panggung dengan tugas melantunkan syair sekaligus menjadi musik internal dari tari tersebut. Penetapan jumlah penari pada Tari Seudati Inong diharuskan genap dengan jumlah sebanyak 8 orang dikarenakan apabila lebih atau kurang dari jumlah tersebut maka pola lantai tidak akan sesuai dengan kaidah yang telah disepakati. Seperti yang dikatakan oleh Hadi dalam Kajian Tari Teks dan Kontekstual bahwa penetapan jumlah penari baik berjumlah genap ataupun ganjil tergantung dengan maksud ataupun keinginan dari penata tari (2007:43). Meskipun tarian di Aceh mayoritas tariannya ditarikan oleh lelaki sebagai alat untuk berdakwah ataupun menyampaikan petuahpetuah akan tetapi, Tari Seudati Inong ditarikan oleh perempuan yang merupakan imitasi dari Tari Seudati yang ditarikan oleh lelaki.

\section{(2). Gerak}

Tari Seudati Inong merupakan imitasi dari Tari Seudati yang ditarikan oleh lelaki sehingga gerak tari yang terdapat pada tarian ini serupa akan tetapi terdapat 


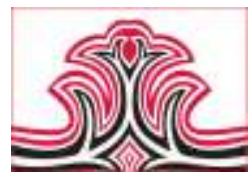

bagian-bagian yang menjadi pembeda. Tari Seudati Inong di kabupaten lain dinamai Tari Laweut, akan tetapi di Kabupaten Aceh Besar tepatnya di Desa Cucum dinamai dengan Seudati Inong. Meskipun Tan Laweut dan Tari Seudati Inong merupakan tarian yang diciptakan berpijak dari Tari Seudati akan tetapi gerakan dari kedua tari tersebut memiliki dan terdapat perbedaan. Hal ini dikarenakan penyebaran dan orang atau syeh yang membawa keduatarian tersebut terletak di kabupaten berbeda sehingga gerakan yang dihasilkan juga berbeda. Kalau Tari Seudati memilliki 8 babakan dalam tiap pertunjukan seperti Saleum Aneuk Saleum Syahi, Saleum Rakan, Bak Saman, Likok, Saman, Kisah, Cahi Panyang, dan juga Lani (Es si Hermaliza, 2014:54-58). Akan tetapi, di Kabupaten Aceh Besar, Tari Seudati Inong hanya memiliki 5 babakan yaitu Saleum Syahi, Saleum Rakan, Likok, Saman dan Lani.

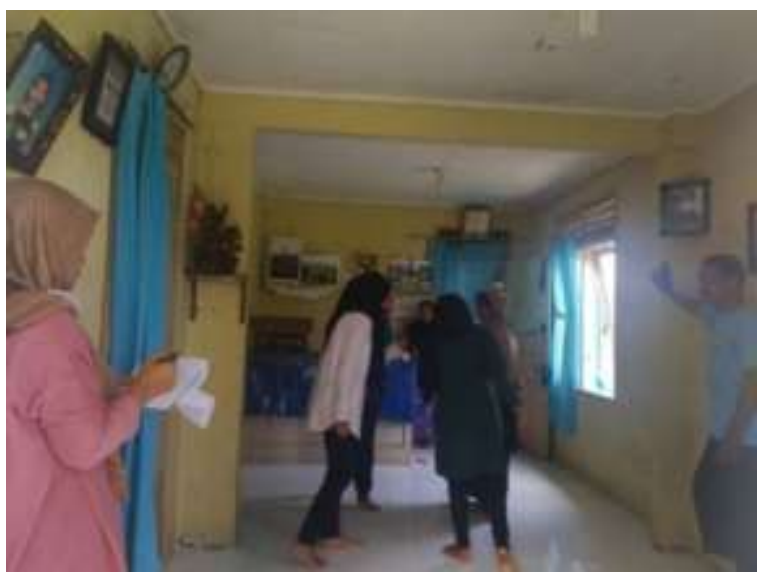

Gambar 4. Latihan Gerak Tari Seudati Inong (Sumber: Nadra Akbar Manalu, 2020)

\section{(3). Tata Rias dan Busana}

Tata rias yang digunakan penari Seudati Inong adalah rias cantik panggung dengan menggunakan pakaian adat Aceh. Busana yang dimaksud adalah pakaian adat Aceh dengan motif khas Aceh yang terdiri atas baju, celana, kain sarung tenun dan jilbab. Tidak ada wama khas dalam pemilihan pakaian pada saat melakukan pertunjukan, akan tetapi warna yang sering digunakan adalah warna merah. walaupun gerak yang dilakukan penari perempuan sama dengan gerak yang dilakukan laki-laki dalam pertunjukan tari Seudati Inong, namun busana penari tetap tertutup dan sopan.
Gorga : Jurnal Seni Rupa

Volume 09 Nomor 02 Juli-Desember 2020 p-ISSN: 2301-5942 | e-ISSN: 2580-2380

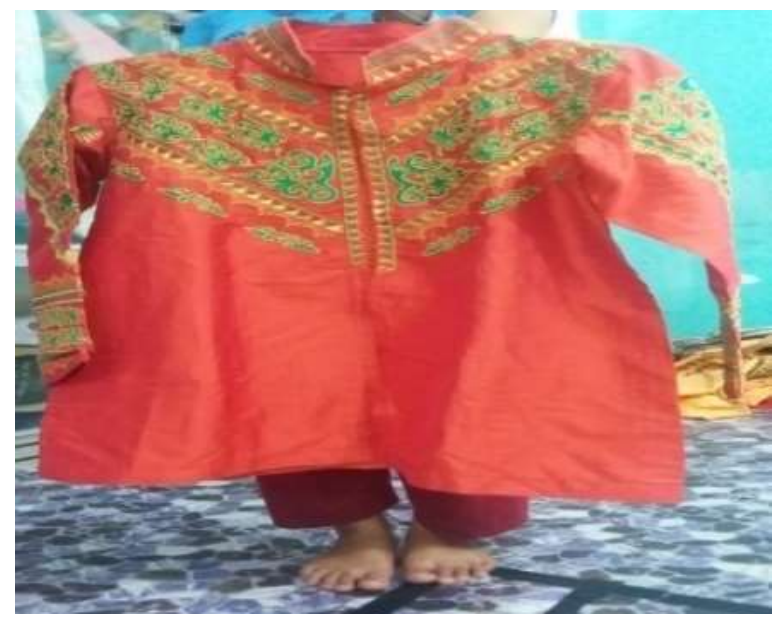

Gambar 5. Baju Tari Seudati Inong

(Sumber: Fatimah Zuhra, 2020)

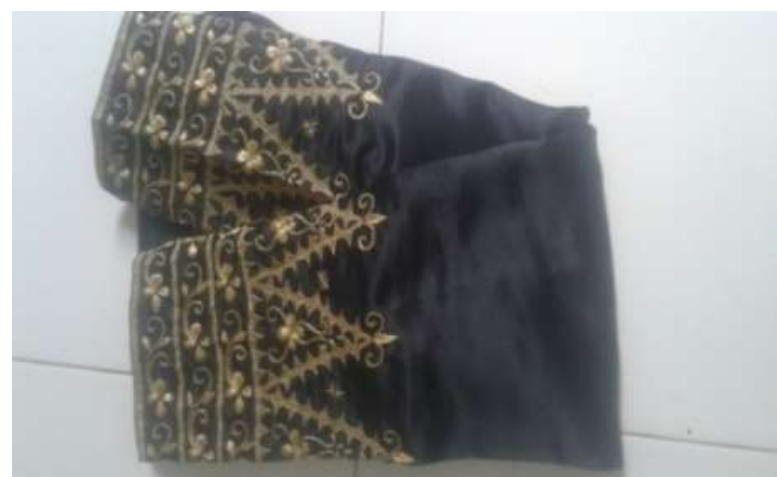

Gambar 6. Celana Tari Seudati Inong (Sumber: Fatimah Zuhra, 2020)

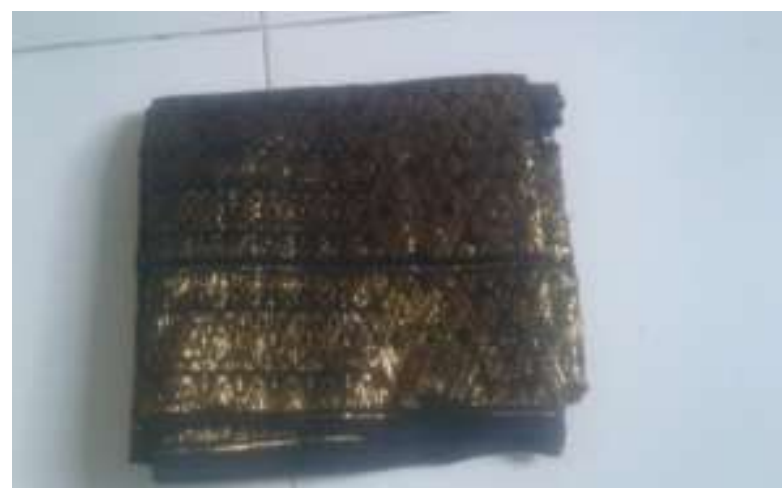

Gambar 7. Songket Tari Seudati Inong (Sumber: Fatimah Zuhra, 2020)

\section{(4). Musik/ Syair}

Sama seperti kebanyakan tarian yang lain di Aceh, Tan Seudati Inong tidak memiliki intrumen musik sebagai pengiring pertunjukan. Meskipun tidak menggunakan intrumen musik, akan tetapi Tari Seudati Inong ini memiliki musik internal. Adapun musik internal yang dimaksud adalah efek dari gerakan-gerakan berupa tepukan paha dan jentikan jari yang dihasilkan oleh para penari ketika bergerak. Selain itu, terdapat syair yang dilantunkan oleh syahi dan dilanjutkan juga oleh 


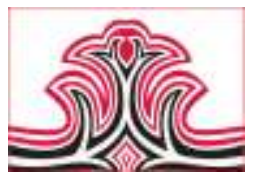

sahutan dari para penari sembari melakukan gerakan yang rampak.

\section{Syair tarian Seudati Inong \\ Saleum Syahi}

Assalamua'laikum intan payong

Ampon lom loen, lah loen Lah loen tamong

Loen tamong lamse intan bulen lom loen,

Lah loen lah loen jak brie,

Loen jak brie saleum intan bulen

Lom keh-lom keh jamee

Nabi khen sunat, puteh lumat lamja

Lamja-lomjarota

Jaroe ta mumat puteh lumat

Lomca-lomca-lomcarat mu,...

Carat mulia $e,,$, raja ampon lomta

Lomtamong-tamong $u$

Tamong udalam dek badan lom $u, \ldots .$.

Lom u dalam $u$ ateh,.......

Keujamee teuka, mubahgia ampon leon ka

Lahka-lahka karena,......

Karena seleum intan bulen lomna

Lomna-lomnabi khen

Uateh tika mubahgia lemti,......

Lemti-lemti kakak

Tika kamoe leng ingan bulen

Lemli-lemli teng on,

Linteng on ieboh cut bang beh

Lom cut bang jak piyoh,......

Ee bang beh lem $u, \ldots . .$.

Lah u-lah u ateh,.....

U ateh tika e,... raja lamra

Lara-lara nubak,......

Ranup bak kamoe malam nyoe ampon

Lom bek-lombek-lombek takoet

Bek takoet pajoh cut bang beh lemha

Laha-laha naka,......

Hana kamoe boh cut bang beh lemra

Lahra-lahracon ngoen,.....

Racoe ngoen tuba e,.... raja ampon lomlah

Lahtan-lahtan loen ba

Tan loen ba sajan dek badan Ampon lomsa-lomsa lah bak

Salah bak tuhan e,... rakan lomhan

Lahhan-lahhan ampon han ampon dosa.

\section{Saleum Rakan}

Assalamu'alaikum loen tamong lamseng

Loen jak brie saleum kejamee teuka

Karena saleum nabi khen sunat

Jaroe tamumat tanda mulia
Gorga : Jurnal Seni Rupa

Volume 09 Nomor 02 Juli-Desember 2020

p-ISSN: 2301-5942 | e-ISSN: 2580-2380

Mulia wareh ranup lampuan

Mulia rakan mameh suara

Ranup kuneng on tawoe bak medang

Ranup aceh besar nee ujoe rasa

Phet dengon meuhong neurasa keudroe

Bak ureng nanggroe bek neucalitra

Nyoe neucalitra bak ureng nanggroe

Malee that kamoe dikee rakyak ba

Ranup bak kamoe bek takoet pajoh

Hana kamoe boh racon ngen tuba

Racon ngen tuba tan meuba sajan

Salah bak tuhan han ampon dosa

Bintang rot timue ijo meukilat

Bintang rot barat ijo meucahya

Dari donya koen sampoe akherat

Beujet ke sahbat geutanyoe dua

Likok

Di di di do dang idi

Nyan la e...e.

Nyan lawe hai nyan

Soe rot jeh soe rot nyan

Pakoen meunan dek e,......

Beutoi meunoe bang ek,.......

Nyan lawe hai adoe

Jak keunoe ku dodo,....

Dodo doidi.

\section{Saman}

Ewa lahu't kaseunut hai apet e,......

E,.....katahe hai cham,....(Syeh)

Hai ma haimatabe hai beulisek (Syahi)

Hai jaroe, jaroe beutajam

Ewa lah cham, walacham camie

Ewa lahi, walahi hilee,...(Syeh)

Ewa lah'ut chamci-chamja milee,.

Alah hiwe-hiwe elawahu't maha

\section{Lani/ Penutup}

Nyoe aceh darussalam

Takembang ngen budaya

Tapasoe syariat islam

Bek udalam budaya luwa.

\section{(5). Tempat Pertunjukan}

Tidak ada batas an mengenai tempat pertunjukan untuk mementaskan Tari Seudati Inong. Hal ini dikarenakan fungsi dari Tari Seudati Inong adalah hiburan sehingga adapun tempat pertunjukannya disesuaikan dengan panggilan hajatan, Jadi tempat pertunjukan dari Tari Seudati Inong bisa dimana saja seperti lapangan, panggung ataupun di arena terbuka lainnya.

4). Tari Seudati Inong sebagai Wujud Representasi Kesetaraan Gender di Kabupaten Aceh Besar 
Menilik tari-tarian di Aceh, mayoritas ditarikan oleh para lelaki dikarenakan fungsi dari tari tersebut merupakan alat untuk berdakwah pada zaman dahulu. Selain itu, Aceh dikenal sebagai Serambi Mekah yang menerapkan syariat Islam dalam berkehidupan di masyarakat, sehingga oleh karena itu pada zaman dulu hampir tidak ada tarian y ang ditarikan oleh perempuan. Seperti y ang dikatakan oleh Sukman (2019:177) bahwa gaya gerak tari di Aceh sesuai dengan ciri khas atau masyarakat Aceh yang menghasilkan gaya gerak atau tari sesuai dengan syariat Islam. Oleh karena itu taritarian di Aceh didominasi oleh tarian yang ditarikan para lelaki. Kemunculan tari-tarian yang ditarikan oleh perempuan seperti Tari Ranup Lampuan, Tari Laweut atau Tari Seudati Inong maupun Tari Ratoh Jaroeh memiliki konteks yang berbeda dengan tari yang ditarikan oleh lelaki yang hakikatnya merupakan alat dakwah pada zaman dahulu dalampenyebaran Agama Is lam di Aceh. Meskipun ditarikan oleh perempuan, akan tetapi gerak yang dilakukan sangat tegas dan rampak salah satunya adalah Tari Seudati Inong yang hadir dengan gerakan yang tegas, gagah dan lembut disaat yang bersamaan.

Seperti yang sudah disampaikan sebelumnya bahwa Tari Seudati Inong ini merupakan tari yang penciptaannya berpijak dan imitasi dari Tari Seudati, sehing gaada beberapa persamaan y ang bisa dilihat dari beberapa aspek gerak maupun makna dibalik dari gerakannya yang energik. Sebelum membahas mengenai Tari Seudati Inong sebagai wujud representasi kesetaraan gender perlu diketahui mengenai latar belakang terciptanya Tari Seudati merupakan sebuah tari perang apabila dilihat dari segi syairnya yang membangkitkan semangat pemuda zaman dahulu untuk melawan penjajah. Oleh sebabitu syair dan gerakan yang terdapat pada Tari Seudati adalah gerakan yang tegas, energik dan mencirikan semangat pemuda untuk tidak gentar melawan penjajah. Hadirnya Tari Seudati Inong dalam kehidupan budaya masyarakat di Aceh Besar merupakan wujud dari representasi kes etaraan gender. Hal ini bisa dilihat dari latar belakang kemunculan atau terciptanya Tari Seudati Inong yang merupakan hasil dari ras a ketertarikan melihat gerakan dari Tari Seudati yang sangat energik hingga timbul rasa keinginan untuk menarikan tari tersebut.

Gender differnces atau sejarah perbedaan gender antara manusia jenis laki-laki dan perempuan terjadi melalui proses yang sangat panjang Pola fikir mas yarakat yang berkembang terhadap pembedaan kedudukan berdas arkan gender membuat terbentukan pembedaan ruang gerak antara kelompok maskulinitas dan
Gorga : Jurnal Seni Rupa

Volume 09 Nomor 02 Juli-Desember 2020

p-ISSN: 2301-5942 | e-ISSN: 2580-2380

femininitas, dimana masyarakat yang mempos is ikan perempuan sebagai seseorang yang lemah lembut, berperan sebagai ibu rumah tan gga, men gurus anak dan melayani suami. Sebaliknya, laki-laki berperan sebagai kepala rumah tangga yang kuat, melindungi keluarga serta memiliki banyak hak is timewa dalam keluarga (Febriani, 2018:5) . Terbentuknya perbedaanperbedaan gender dikarenakan oleh banyak hal, diantaranya dibentuk, disosialisasikan, diperkuat, bahkan dikontruksi secara sosial atau kultural melalui ajaran agama ataupun negara. Melalui proses panjang keberadaan gender yang berkembang akhimya dianggap menjadi ketentuan Tuhan.

Kesetaraan gender adalah kondisi perempuan dan lakilaki menikmati status y ang setara dan memiliki kondisi yang sama untuk mewujudkan secara penuh hak-hak asasi dan potensinya bagi pembangunan disegala bidang (Pratiwi, 2017:215). Tari seudati inong dapat direpresentasikan sebagai bentuk kesetaraan gender yang berkembang dimasyarakat Aceh Besar dalam konteks seni pertunjukan. Bentuk gerak tari Seudati yang energik memiliki kesamaan dengan bentuk tari Seudati Inong. Tidak ada batasan gerak ataupun nang pertunjukan pada tari seudati inong untuk perempuan di Aceh Besar, dapat dikatakan peran dan kemampuan laki-laki sama dengan peran dan kemampuan perempuan yang tercermin dalam bentuk tari seudati inong.

\section{Pembahasan}

\section{1). Bentuk Penyajian Tari Seudati Inong}

Bentuk Penyajian tari Seudati Inong memiliki 5 struktur langkah; 32 gerakan mulai dari salam syahi, salam rakan, likok, saman, dan lani.

\section{(1). Salam Syahi}

dan diring dengan dua vocal (syahi) lalu berdiri dua per syaf dan merentangkan tangan sejajar lalu diayunkan kedepan dan memetik jari, beriringan dengan melangkah kedepan dan kaki belakang terangkat dan kembali ke posisi semula. dalamkeadaan berbaris satu per syaf s ambil memberikan salam, selanju tnya dengan penari serentak melangkahkedepan dan diikuti dengan memetik jari, selanjutnya mengayunkan tangan dan juga diikuti kaki mundur dari satu per s yaf menjadi dua per syaf. Selanjutnya kembali, lalu merobah posisi menjadi dua per syaf kembali lalu merobah posisi menjadi jambo dengan langkah dan ayunan tangan yang sangat indah.

Setelah posisi besar /lebar terbentuk, langsung membuat lingkaran dan berjalan satu kali putaran langsung membuat kombinas, Syeh memberikan abaaba untuk melangkah kedepan dengan petik jari, ayunan tangan dan mundur satu langkah ini diulang 


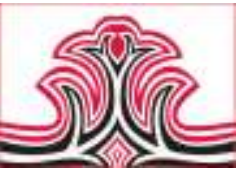

sebanyak $2 \frac{1}{2}$ kali dengan cepat lalu berhenti dan syeh memberi aba-aba menepuk paha dan disambut oleh penari lainny a, lalu berputar ditempat satu kali, kembali melangkah kedepan dan kebelakang. Syeh memberikan kembali aba-aba menepuk paha dua kali langsung berjalan saling berhadapan dan berputar dengan kawan lalu kembali keposisi s emula dan memutarkan langkah, juga petik jari dan ayunan tangan yang lemah gemulai dan melangkah kearah kanan tiga langkah dan kekiri tig a langkah dan ini diulang sampai dengan syair yang sangat cepat dan tiba-tiba berhenti.

\section{(2). Salam Rakan}

Salam rakan merupakan berdiri dua per syaf lalu Syeh memberi kode untuk melangkah kedepan, sambil mengangkat tangan keatas dan menurunkan dengan perlahan sambil diiringi dengan vokal saling bers ahutan dengan vokalis (Syahi) dan penari langsung merubah gerak, selanjutnya mengangkat tangan dari arah bawah keatas dengan petik jari. Melangkah dengan kaki kiri mengangkat kaki kanan, gerakan ini diulang sampai tiga kali langsung dan selanjutnya kembali berjalan dengan ragamgerak tiga langkah dan mundur tiga langkah, lalu disertai deng an pukulan paha dan diulang sampai dua kali.

Penari berubah posisi dengan pola empat sebelah kiri dan empat sebelah kanan, saling berhadapan. Sebelah kanan maju kekiri dan sebelah kiri maju kekanan ini diulang dua kali dan langsung berubah posisi ke awal, kembali dalam keadaan yang kencang dan cepat lalu dihabiskan pertanda salam, rakan habis.

\section{(3). Likok}

Likok merupakan setelah duabaris per syaf langsung mengangkat tangan kiri sejajar dengan bahu dan menggoy angkan kepala dengan lembut diiringi dengan petik jari dalam keadaan tangan kiri direntangkan kedepan, penari pun melangkah tiga langkah kedepan lalu meloncat kebelakang tiga kali dan disertai vokal, lalu berubah A atau Udan T.Penari melangakah kekin tiga langakah sambil mengayunkan tangan kedepan di ulang sampai tiga kali dalam gerakan yang cepat dan berhenti pertanda likok sudah seles ai.

\section{(4). Saman}

Saman merupakan berdiri dua per syaf lalu syeh memberikan aba-aba untuk membawakan saman sekaligus dengan petikjari dan lengan dan langkah kaki yang sama juga diiringi dengan pukulan paha yang serentakjuga salin berputar dan kombinasi yang serasi dengan saman apayang kita bawa, tiga kali lambat dan tiga kali cepat dan di akhiri dengan serentak.
Gorga : Jurnal Seni Rupa

Volume 09 Nomor 02 Juli-Desember 2020 p-ISSN: 2301-5942 | e-ISSN: 2580-2380

\section{(5). Iani}

Lani leter persegi pecah menjadi banjar barisan di belakang satu barisan y ang didepan apit dan s yeh, serta tepuk tangan berhenti lansung habis dan terakhir pulang selesai.

\section{2). Tari Seudati Inong sebagai Wujud Representasi Kesetaraan Geder di Kabupaten Aceh Besar}

Penyajian tari Seudati Inong oleh perepuan sangat berbeda dengan tarian Tradisional Aceh lainnya. Wilayah yang dikenal sangat Is lami dapat memberikan ruang terhadap kaum perempuan dalam ruang pertunjukan seni khus usnya seni tari. Peremuan dalam menarikan tari Seudati Inong mewakili gambaran bahwa kemampuan perempuan sama dengan laki-laki dalam menjalankan perannya masing-masing, perempuan saat ini bukan lagi kaumyang beradadalam batas an sempit yang hanya diberi lebel "ibu rumah tangga" tetapi sudah mampu berperan ganda dan berada diposisi yang juga memilki peran kuat dalam kehidupan. Gender adalah kontruksi atau tatanan sosial mengenai berbagai perbedaan yang mengacu kepada relasi-relasi sosial antara perempuan dan laki-laki, atau suatu sifat yang telah ditetapkan secara sosial ataupun budayaElizabeth (dalamudoyo 2011:21). Tari Seudati Inong ditarikan oleh perempuan dan dapat diterima dengan baik di setiap kalangan masyarakat sebagai wujud kesetaraan gender.

\section{KESIMPULAN DAN SARAN 1.Kesimpulan}

Tari Seudati Inong kesenian tradisi Aceh yang berkembang di desa Cucum kecamatan Kota Jantho Kabupaten Aceh Besar. Buniamin merupakan seorang seniman tinggal di desa Cucum dan telah bertahuntahun memperkenalkan dan mengajarkan tari Seudati Inong kepada anak-anak remaja di des a tersebut. Tari Seudati ditarikan oleh laki-laki dan tari Seudati Inong ditarikan oleh perempuan. TariSeudati Inong dikenal sebagai bentuk tarian tradisional Aceh dari penani laki-laki beralih ditarikan oleh perempuan. dengan bentuk penyajian yang sama namun memiliki perubahan dan keunikan yang berbeda seperti bentuk gerak tari Seudati yang energik memiliki kesamaan dengan bentuk tari Seudati Inong. Tidak ada batasan gerak ataupun ruang pertunjukan pada tari Seudati Inong untuk perempuan di Aceh Besar, dapat dikatakan peran dan kemampuan laki-laki sama dengan peran dan kemampuan perempuan yang tercermin dalam bentuk tari Seudati Inong .

\section{Saran}

Diharapkan semoga dengan adanya penelitian ini mampu memberikan kontribusi terhadap 
perkembangan kesenian tari dilingkungan mas yarakat Aceh, khus usnya mas yarakat desa Cucumkecamatan Kota Jan tho kabupaten Aceh Besar agar kes eniaannya dapat lebih dikenallagidiseluruh lapisan mas yarakat, baik masyarakat lokal maupun masyarakat luar dari wilayah Aceh. Diharapkan penelitian ini dapat menjadi sumber bacaan atau refrensi karya ilmiah untuk penelitian selanjutnya dalam mengkaji Tari Seudati Inong. Harapan untuk pemerintah daerah dapat memberikan perhatian perkembangan kesenian khusus untuk peningkatan dan kesejahteraan para seniman-seniman di desa Cucum Kecamatan Kota Jantho Kabupaten Aceh Besar.

\section{DAFTAR RUJUKAN}

Febriani, Rahmi. (2018). Wong Tengger: Sebuah Role Model Kesetaraan Gender.

EssiHermaliza. (2014). Seudati di Aceh. Banda Aceh: Balai Pelestarian Nilai Budaya Banda Aceh

Hadi, Y. Sumandiyo, (2007). Kajian Tari Teks dan Konteks. Yogyakarta: Press FSP ISI Yogyakarta.

Jazuli, M. (2008). Paradigma Kontekstual Pendidikan Seni. Semarang: Unesa University Press.

Maryono. (2012). Analisa Tari. Surakarta: ISI Press Surakarta

Murgiyanto, Sal. (2018). Pertunjukan Budaya Dan Akal Sehat. Jakarta: FSP-IKJ

Pratiwi, Happy Atma. (2017). Represntasi Kesetaraan Gender pada Iklan (Tinjauan Semiotika Citra Laki-Laki dalam Keluarga pada Iklan Televisi). Jurnal Desain,_( _ ), 212-230.

Rusdi. (2019). Aceh Besar, Sejarah, Adatdan Budaya. Aceh Besar: Dinas Pendidikan dan Kebudayaan Aceh Besar.

Sugiyono. (2014). Metode Penelitian Kuantitatif Kualitatif Dan $R \& D$. Bandung: Alfabeta.

Sukman. (2019). Exis tence Of Ratoh Bantai Dance In The Studio of Buana Banda Aceh. Jurnal Ilmu Pengetahuan dan Karya Seni, 21(2), 175-185.

Udoyo S. (2011). Representasi des a Dalam Film Tari "Dongeng Dari Dirah" Analisis Semiotika Barthesian. Jurnal Seni Media Rekam,_(_ ), 5160. 